\title{
Evolution Patterns of Frost-Heaving Pressure with Partial Ponding in Cold Region Tunnels
}

\author{
Xinyu Zheng, ${ }^{1}$ Fei Xu $\mathbb{D}^{2,3,4}$ Songtao Shi, ${ }^{5}$ Yang Gao, ${ }^{4}$ and Qi Li ${ }^{5}{ }^{5}$ \\ ${ }^{1}$ Geotechnical and Structural Engineering Research Center, Shandong University, Jinan 250061, Shandong, China \\ ${ }^{2}$ Key Laboratory of Highway Bridges and Tunnels of Shaanxi Province, Chang'an University, Xi'an 710054, China \\ ${ }^{3}$ State Key Laboratory for Geomechanics and Deep Undergroud Engineering, China University of Mining and Technology, \\ Xuzhou 221116, Jiangsu, China \\ ${ }^{4}$ Key Laboratory of Large Structure Health Monitoring and Control, Shijiazhuang Tiedao University, Shijiazhuang 050043, \\ Hebei, China \\ ${ }^{5}$ School of Civil Engineering, Shijiazhuang Tiedao University, Shijiazhuang 050043, Hebei, China
}

Correspondence should be addressed to Fei Xu; xufei@stdu.edu.cn

Received 24 October 2021; Accepted 29 January 2022; Published 23 February 2022

Academic Editor: Yu Wang

Copyright (C) 2022 Xinyu Zheng et al. This is an open access article distributed under the Creative Commons Attribution License, which permits unrestricted use, distribution, and reproduction in any medium, provided the original work is properly cited.

\begin{abstract}
The calculation of the frost-heaving pressure is one of the key issues in the frost-resistant design of tunnels in cold regions. To reveal the frost heave mechanism of partial ponding behind the tunnel linings, a three-dimensional geo-mechanical model test was developed that only considered the frost heave load. A self-designed water bladder equipment was set up to simulate the partial ponding. The frost heave response characteristics of the surrounding rock with partial ponding were simulated to analyze the change law of temperature field and frost-heaving pressure under freezing by using air-conditioning to reduce the ambient temperature of the model test. The changes in the internal temperature of the surrounding rock and the evolution of the frostheaving pressure over time under different thicknesses of partial ponding and different levels of surrounding rock were compared. The theoretical calculation value of frost-heaving pressure and the test values of the model test were compared and analyzed using the numerical simulation method. The results showed that the temperature of the surrounding rock presented three-stage changes, which showed a lagging characteristic relative to the environmental temperature. The empirical equation for the relationship between the frost-heaving pressure and time was obtained by nonlinear fitting of the experimental results. Taking advantage of the regular tetrahedron calculation model, the paper established a semiempirical frost-heaving pressure model considering time and space effects, which was identical with the frost-heaving phenomenon from the experiments. Theoretical analysis, experiments, and numerical simulation show that the frost-heaving pressure increased along with the depth of partial ponding and the elastic resistance coefficient of surrounding rock, which could provide references for revealing the frost-heaving pressure of partial ponding behind tunnels of cold regions and has a significant meaning in the engineering application.
\end{abstract}

\section{Introduction}

China has vast cold regions where a series of tunnels have been built during the transportation network construction [1-3]. However, cold region tunnels in western and northeastern China have frequent frost damages to varying degrees [4-6], resulting in structural cracks, water leakage, road icing, and ice blockage of the drainage pipes [7]. Therefore, the calculation and evaluation of frost-heaving pressure is an important research question that requires an urgent solution in cold region tunnel engineering and is of great significance for studying the evolution patterns of tunnel frost damage.

To obtain a reasonable frost-heaving pressure, it is necessary to accurately understand the frost heave mechanism of tunnels in cold regions $[8,9]$. In recent years, research on alpine region tunnels has produced fruitful results, which provided some theoretical references to the frostheaving pressure on tunnel linings in cold regions [10]. The existing frost-heaving pressure calculations are based on the 
water-bearing weathered layer model, the partial ponding behind the lining model, or the freeze-thaw circle overall frost heave model. The water-bearing weathered layer model was proposed based on the surveys of tunnels in Japan. Tunnels suffering from frost-heaving often have a weathered layer in the surrounding rock, and the frost heave generally occurs on the sidewalls and less frequently on the vault. Zhang et al. [11] proposed a calculation model for the frostheaving pressure regarding the frost heave layer and lining as an elastic body. Zhang et al. [12] established a frost heave model based on the weathered layer and broken layer, with the freezing depth of surrounding rock as a parameter. The freeze-thaw circle overall frost heave model considers the frost-heaving pressure as the result of the overall expansion of the water-bearing surrounding in the freeze-thaw circle. Lai et al. [13] deduced the formula for the frost-heaving pressure of cold region tunnels through numerical inversion. The different cognitions of frost heave deformation have led to different frost-heaving pressure solutions of the freezethaw circle overall frost heave model, and experts and scholars have systematically analyzed and summarized those methods and their assumptions and applicability [14-18]. The partial ponding behind the lining attributes the frostheaving pressure to the freezing and swelling of the locally accumulated water between the lining and the surrounding rock, where the lining structure restricts the swelling, thereby forming the frost-heaving pressure on the lining structure [19]. Based on the frost heave hypothesis of partial ponding space, Wang et al. [20] proposed a solution for the frost-heaving pressure, which initiated the partial ponding frost heave theory. Fan [21] and Deng et al. [22] revised the frost-heaving pressure calculation model of partial ponding space. Therefore, the frost heave theories are based on hypothetical models, and their applications are also different. In addition to the frost heave theories, scholars have adopted other methods to study the frost-heaving pressure mechanism of cold region tunnels [23-25]. Chen et al. [26] discussed the variation of the temperature field in the Tiziling tunnel with time, tunnel length, and depth on surrounding rock. Yan et al. [27] conducted in-situ tests on the frostheaving pressure of the moraine at the portal of the Que'ershan Tunnel and obtained the thickness of the freezethaw circle, frost-heaving pressure, and the stresses inside and outside the lining structure before and after freezing. Qiu et al. [28] conducted indoor frost heave tests for tunnels with different cross-sections and analyzed the distribution of frost-heaving pressure on the lining. Qu et al. [29] simulated the frost-heaving pressure on the lining through indoor model tests and obtained the distribution pattern of the frost-heaving pressure on the lining. Therefore, the existing research focused more to the calculation of the maximum frost-heaving pressure, and few reflected the temporal and spatial evolution patterns of the generation and development of the frost-heaving pressure.

Affected by the temperature field of the tunnel, the frostheaving pressure also presents a three-dimensional temporal and spatial distribution. In fact, the frost heave behind the lining may be one of the main reasons for the frost heave of cold region tunnels. To study the frost-heaving pressure characteristics of partial ponding behind the tunnel lining in cold regions, a three-dimensional geo-mechanical model test on the frost-heaving pressure of locally accumulated water behind the lining was firstly carried out. The temperature distribution pattern and the frost-heaving pressure variation characteristics of the surrounding rock were acquired during the freezing process. After the nonlinear fitting of the frostheaving pressure from the test, a new semiempirical frost heave model was established based on the existing frost heave model. Considering the time-space effect, the frostheaving pressure variation pattern with the volume of partial ponding and time was finally obtained. This study could provide a new idea for analyzing the frost-heaving pressure of lining void in cold region tunnels.

\section{Test Materials}

2.1. Similarity Ratio. The model size is an important factor affecting the accuracy of model test results. In this test, factors such as the similarity requirements of model materials and the burying and layout of test components were comprehensively considered. Only by considering the similarity criteria that have a greater impact on the test results can their reliability be guaranteed. Therefore, the geometric similarity ratio was set at 110 . Based on the similarity ratio theory, the similarity ratio of other physical and mechanical parameters was calculated according to the geometric similarity ratio. The similarity ratios of key parameters are listed in Table 1.

2.2. Materials. The main factor to control in the preparation of surrounding rock equivalent material was the similarity of volume-weight and mechanical strength. The physical and mechanical parameters of grades III, IV, and $\mathrm{V}$ surrounding rock were selected as the reference to set the parameters for the prototype material in the partial ponding frost heave test. The equivalent material for the surrounding rock was prepared with reference to the results of the literature [30]. Barite powder, silica sand, and iron powder were selected as the aggregates, and gypsum, paraffin oil, and rosin were selected as the cementing agents for the surrounding rock model. Specifically, $m_{b}, m_{i}, m_{s}$, $m_{g}$, and $m_{c}$ are the mass of barite powder, iron powder, silica sand, gypsum powder, and coarse quartz stone, respectively. The mass proportions of rosin in the cement are $20 \%, 17 \%$, and $5 \%$, respectively. The compounding ratio of the equivalent material is shown in Table 2. The physical and mechanical parameters of the surrounding rock prototype and equivalent material are acquired from $\mathrm{GB} /$ T50218-2014 standard for engineering classification of rock mass and shown in Table 3.

According to previous research results [31], the mixture of gypsum, diatomaceous earth, and water can simulate the lining. After a large number of compounding ratio tests, a mixture with the mass ratio of gypsum: diatomaceous earth: water $=1: 0.4: 2.4$ was prepared to simulate the secondary lining. The elasticity modulus of the model material was $0.63 \mathrm{GPa}$, and the compressive strength was $0.61 \mathrm{MPa}$. 
TABle 1: Model scales.

\begin{tabular}{lccc}
\hline Parameter & Symbol & Similarity ratio & Calculation method \\
\hline Length & $C_{l}$ & 110 & Comprehensive factor method \\
Density & $C_{\gamma}$ & 1 & - \\
Pressure & $C_{p}$ & 110 & $C_{p}=C_{l} C_{\gamma}$ \\
Strain & $C_{\varepsilon}$ & 1 & - \\
Elastic modulus & $C_{E}$ & 110 & $C_{E}=C_{p} / C_{\varepsilon}$ \\
Temperature & $C_{T}$ & 1 & - \\
\hline
\end{tabular}

TABLE 2: The mass ratio of similar materials in surrounding rock.

\begin{tabular}{|c|c|c|}
\hline \multirow[t]{2}{*}{ Classification } & & Material mass ratio \\
\hline & III & $m b: m i: m s: m g: m c=59.5: 25.5: 7.5: 1.5: 6.0$ \\
\hline Surrounding rock level & IV & $m b: m i: m s: m g: m c=40.9: 40.9: 10.2: 2.5: 5.5$ \\
\hline & $\mathrm{V}$ & $m b: m i: m s: m g: m c=40.9: 40.9: 10.2: 2.5: 5.5$ \\
\hline
\end{tabular}

TABLE 3: Material parameters.

\begin{tabular}{|c|c|c|c|c|}
\hline Type & & & Weight capacity $/ \gamma\left(\mathrm{kN} / \mathrm{m}^{3}\right)$ & Elastic modulus/MPa \\
\hline \multirow{6}{*}{ Surrounding rock level } & \multirow{2}{*}{ III } & Prototype & 26.0 & 16,000 \\
\hline & & Model & 24.6 & 157 \\
\hline & \multirow{2}{*}{ IV } & Prototype & 25.0 & 4000 \\
\hline & & Model & 23.9 & 41 \\
\hline & \multirow{2}{*}{$\mathrm{V}$} & Prototype & 20.0 & 2000 \\
\hline & & Model & 23.2 & 17 \\
\hline
\end{tabular}

\section{Model Test Design}

3.1. Test Platform and System. The test device was equipped with a refrigeration system and temperature and pressure test systems. The refrigeration system consists of a compressor, a fan, and a temperature control system. The lowtemperature environment test chamber was controlled by the temperature control panel, and the cold air produced by the compressor was discharged through the fan. The temperature range was $-30^{\circ} \mathrm{C}$ to $50^{\circ} \mathrm{C}$, and the temperature control accuracy was $\pm 1^{\circ} \mathrm{C}$. According to the size of the lowtemperature environment test chamber, the geometric size of the model box was determined to be $500 \mathrm{~mm} \times 500 \mathrm{~mm} \times 600 \mathrm{~mm}$, and the model box was wrapped with $50 \mathrm{~mm}$ thick thermal insulation polyurethane. The test setup is shown in Figure 1.

According to Saint-Venant's principle, the sphere of influence during cavern excavation is about three to five times the diameter of the cavern from the center. The actual size of the model is shown in Figure 2. The outside diameter of the lining was $100 \mathrm{~mm}$, the inside diameter was $90 \mathrm{~mm}$, and the lining thickness was $5 \mathrm{~mm}$. Since the distance between the tunnel and the boundary in the model exceeds five times the tunnel radius, the influence of the boundary on the test results was eliminated.

3.2. Partial Ponding Model Making. A superabsorbent polymer (SAP) was used as the superabsorbent material. Indoor water absorption and frost heave tests showed that the frost heave factor per unit volume of SAP and water mixture was basically the same as that of pure water. Therefore, the jelly of water and SAP in plastic bags can be

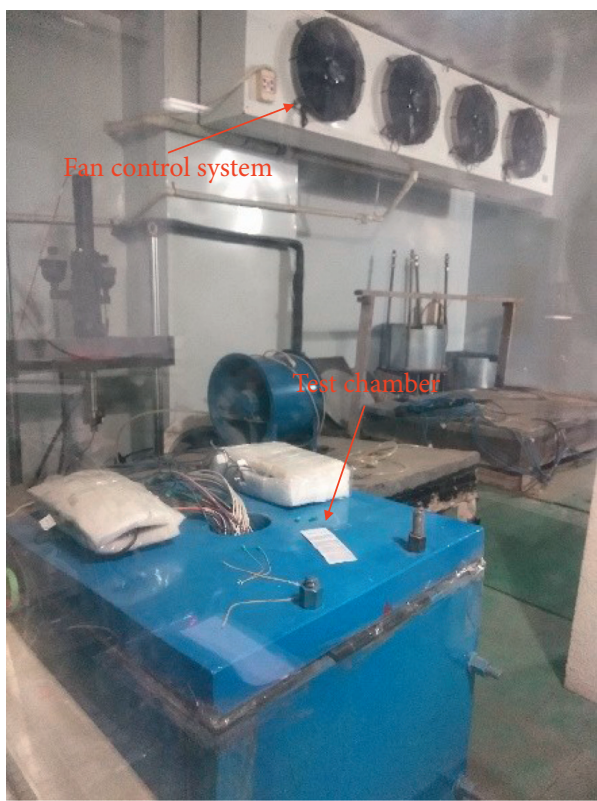

Figure 1: Field test.

used as the material for modelling lining void behind the tunnel.

3.3. Test Items. To study the frost-heaving pressure of partial ponding behind the tunnel, we conducted model tests under 12 different test items based on three surrounding rock grades (grades III, IV, and V) and three accumulated water thicknesses $(20 \mathrm{~mm}, 30 \mathrm{~mm}$, and $40 \mathrm{~mm})$. The spatial size was calculated according to the model in literature, and 


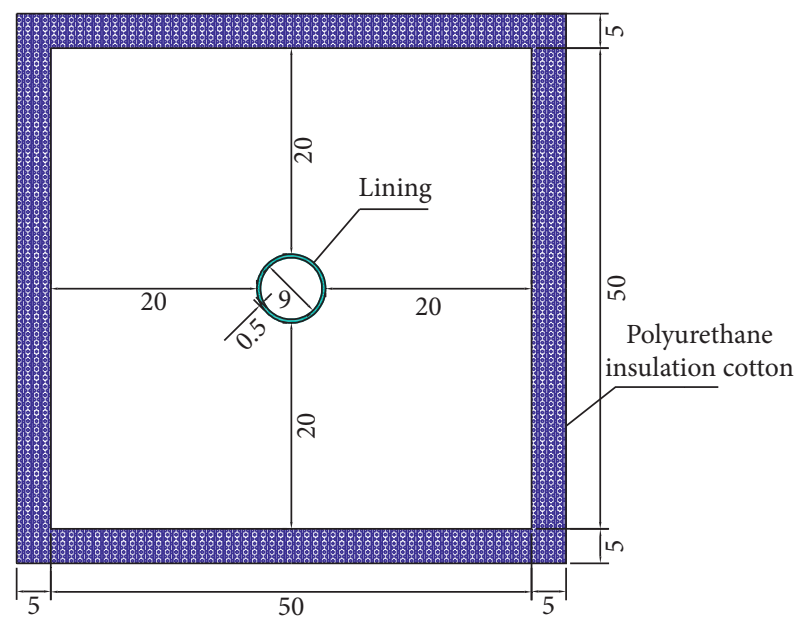

FIGURE 2: Schematic diagram of model test cross-section size (unit: $\mathrm{cm})$.

materials of different surrounding rock grades were evenly filled on both sides of the test box. The designed parameters of each working condition are shown in Table 4. JLBS-MD$50 \mathrm{~N}$ miniature earth pressure sensors were installed between the lining and the partial ponding space, which had a range of $50 \mathrm{~N}$ and a resolution of $0.1 \mathrm{~N}$, and the size of the pressure surface is $16 \mathrm{~mm} \times 6 \mathrm{~mm}$.

A total of 15 temperature sensors were installed on three typical cross-sections of the surrounding rock. The distance of the three sections $100 \mathrm{~mm}, 300 \mathrm{~mm}$, and $500 \mathrm{~mm}$ from the tunnel portal section. The three sets of temperature sensors were labeled as follows. Temperature sensors installed on the cross-section $100 \mathrm{~mm}$ from the portal were labeled Tl\# to T5\#; temperature sensors installed on the cross-section $300 \mathrm{~mm}$ from the portal were labeled T6\# to T10\#; temperature sensors installed on the cross-section $500 \mathrm{~mm}$ from the portal were labeled T11\# to T15\#; one additional sensor was used to monitor the temperature inside the environmental chamber, which was labeled T16\#. The transverse lengths from the temperature sensors were $5 \mathrm{~mm}, 15 \mathrm{~mm}$, $25 \mathrm{~mm}, 45 \mathrm{~mm}$, and $75 \mathrm{~mm}$, respectively. The selected temperature sensors were PT100 models with the range of $-55^{\circ} \mathrm{C}$ to $200^{\circ} \mathrm{C}$ and the resolution of $0.1^{\circ} \mathrm{C}$.

3.4. Test Procedure. The main steps of the test include lining mold preparation and model pouring, surrounding rock material preparation, material filling, sensor installation, temperature control process, and data acquisition, as shown in Figures 3 and 4 . The specific process is as follows:

\section{Results and Analysis}

4.1. Temperature Changes at the Cross-Sections. The temperature distribution on typical cross-sections $100 \mathrm{~mm}$, $300 \mathrm{~mm}$, and $500 \mathrm{~mm}$ from the tunnel portal were analyzed, as shown in Figures 5 to 7 . The results showed that the environmental temperature dropped rapidly during the $50 \mathrm{~h}$ cooling process and reached the lowest setting in the test after $10 \mathrm{~h}$, fluctuating in the range from -15 to $-17^{\circ} \mathrm{C}$. The temperature rose rapidly after the refrigerator in the environmental chamber was turned off and eventually stabilized at about $5^{\circ} \mathrm{C}$. As shown in the figures, the initial temperature of the surrounding rock is about $10^{\circ} \mathrm{C}$. The temperature of the three typical cross-sections showed similar trends with the decrease of environmental temperature, rapidly dropping to $0^{\circ} \mathrm{C}$ before gradually stabilizing. The reason was that the water froze into ice and absorbed a lot of heat at $0^{\circ} \mathrm{C}$, at which time the surrounding rock maintained a relatively balanced temperature. As the freezing process continued, the temperature at each measurement point continued to drop rapidly, and the surrounding rock reached the lowest temperature. However, these changes showed hysteresis characteristics relative to the ambient temperature.

Figure 5 shows that the lowest temperatures are $-10.2^{\circ} \mathrm{C}$, $-7.6^{\circ} \mathrm{C},-6.8^{\circ} \mathrm{C},-6.1^{\circ} \mathrm{C}$, and $-5.2^{\circ} \mathrm{C}$. Measurement points closer to the lining showed lower temperatures. The reason was that the cold air transferred a large amount of heat to the inside of the surrounding rock through the lining while releasing energy to lower the temperature of the surrounding rocks. Figures 6 and 7 show similar trends. The difference is that the lowest surrounding rock temperatures at the crosssection $300 \mathrm{~mm}$ from the entrance are $-4.8^{\circ} \mathrm{C},-4.0^{\circ} \mathrm{C}$, $-3.3^{\circ} \mathrm{C},-2.7^{\circ} \mathrm{C}$, and $-2.6^{\circ} \mathrm{C}$, and those at the cross-section $500 \mathrm{~mm}$ from the entrance are $-4.4^{\circ} \mathrm{C},-2.4^{\circ} \mathrm{C},-0.9^{\circ} \mathrm{C}$, $-0.2^{\circ} \mathrm{C}$, and $0.8^{\circ} \mathrm{C}$. Comparison of the lowest temperature at each cross-section showed that the temperature gradients of the cross-sections $300 \mathrm{~mm}$ and $500 \mathrm{~mm}$ from the entrance relative to the cross-section $100 \mathrm{~mm}$ from the entrance were $-0.027^{\circ} \mathrm{C} / \mathrm{mm}$ and $-0.0145^{\circ} \mathrm{C} / \mathrm{mm}$, respectively. The temperature of the surrounding rock gradually decreased along the direction of the tunnel, and the energy transfer was weakened. Thus, a temperature gradient with a $54 \%$ temperature drop was formed. The readings of all measurement points inside the surrounding rock were subzero for a period of time, which was the prerequisite to ensure that the locally accumulated water was fully frozen.

\subsection{Analysis of the Temporal and Spatial Characteristics of the} Frost-Heaving Pressure. During frost heaving, the water storage space generated frost-heaving pressure due to the constraints of the lining and the surrounding rock. The expansion of the frozen water generated pressure on the lining and the surrounding rock, and the measured pressure could reflect the trend of the frost-heaving pressure. The evolution of frost-heaving pressure with time under each working condition at each cross-section is shown in Figure 8. The frost-heaving pressure was zero at each pressure measurement point in the early stage of frost heaving because the locally accumulated water was liquid and had not frozen in the early stage. With the decrease of temperature, the frostheaving pressure increased rapidly and remained constant after reaching the peak value, which reflected the evolution process of the frost-heaving pressure after the water was frozen. The frost-heaving pressure increased nonlinearly with time, which reflected the process of freezing pressure growth. Based on the test results and nonlinear regression fitting, an empirical equation of the frost heave pressure 
TABle 4: Design of test items.

\begin{tabular}{|c|c|c|c|c|c|}
\hline \multirow{2}{*}{ Test items } & \multirow{2}{*}{ Surrounding rock level } & \multirow{2}{*}{ Thickness } & \multicolumn{2}{|c|}{ Partial ponding space $/ \mathrm{mm}$} & \multirow{2}{*}{ Distance from the portal section $/ \mathrm{mm}$} \\
\hline & & & Circumferential length & Longitudinal length & \\
\hline 1 & III & 40 & 49 & 49 & \multirow{2}{*}{100} \\
\hline 2 & IV & 40 & 49 & 49 & \\
\hline 3 & III & 30 & 37 & 37 & \multirow{2}{*}{300} \\
\hline 4 & IV & 30 & 37 & 37 & \\
\hline 5 & III & 20 & 25 & 25 & \multirow{2}{*}{500} \\
\hline 6 & IV & 20 & 25 & 25 & \\
\hline 7 & III & 20 & 25 & 25 & \multirow{2}{*}{100} \\
\hline 8 & $\mathrm{~V}$ & 40 & 49 & 49 & \\
\hline 9 & III & 30 & 37 & 37 & \multirow{2}{*}{300} \\
\hline 10 & $\mathrm{~V}$ & 30 & 37 & 37 & \\
\hline 11 & III & 40 & 49 & 49 & \multirow{2}{*}{500} \\
\hline 12 & $\mathrm{~V}$ & 20 & 25 & 25 & \\
\hline
\end{tabular}

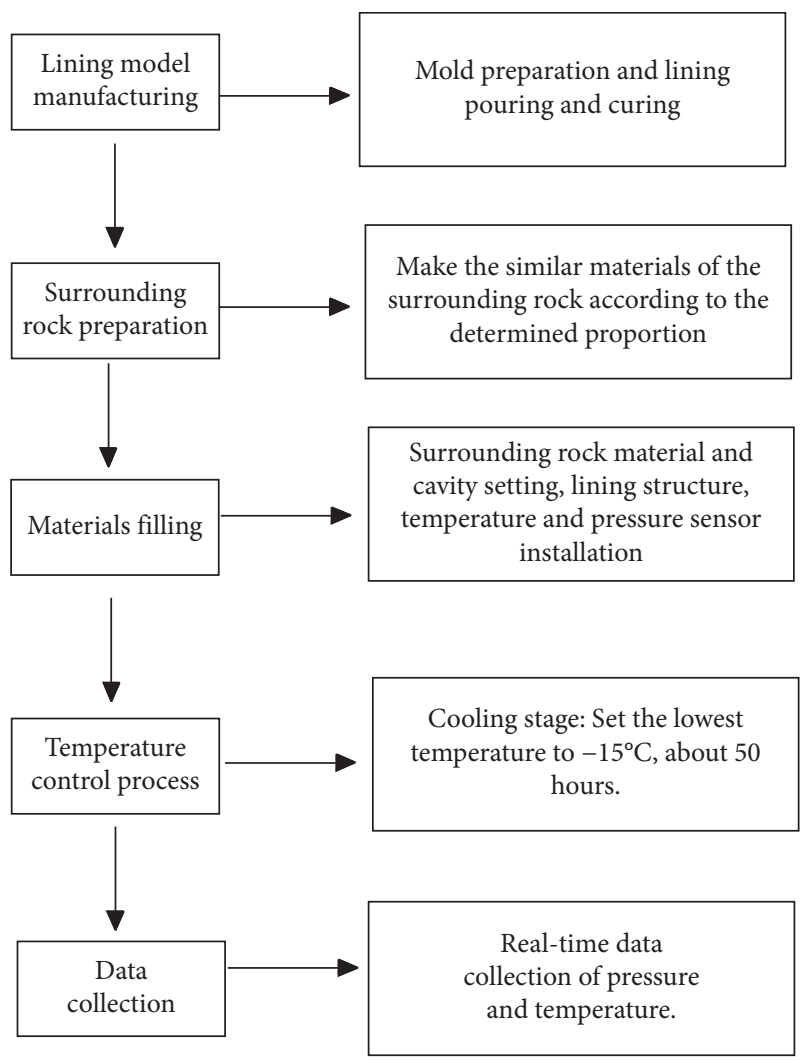

Figure 3: Model test process.

evolution pattern of locally accumulated water considering the time effect was established as follows:

$$
\sigma_{f}=\frac{P_{f}}{1+e^{-n\left(t-P_{t}\right)}},
$$

where $P_{f}$ is the maximum frost-heaving pressure generated by the frost heaving in the accumulated water space [32], $n$ is the coefficient representing the steepness of the frostheaving pressure curve, $P_{t}$ is the moment when the frostheaving pressure increased most rapidly, and $t$ is the freezing time.

The fitting results of each working condition are shown in Table 5. With correlation coefficients $\left(R_{2}\right)$ all above 0.91 , the fitted curves can well reflect the evolution characteristics of frost-heaving pressure. Although temperature affected the time point when the frost heave curve rose and the freezing time $P_{t}$, the peak was affected by the water storage space and the restraint stiffness of the surrounding rock.

\section{Analysis of the Frost-Heaving Pressure}

5.1. Semiempirical Model of Time-Space Effects. Considering the interaction between the lining, the water with frost heaving, and the surrounding rock, a three-dimensional frost heave model based on a regular tetrahedron was derived in literature. Based on the derivation of the frost-heaving pressure and the relationship between the water storage space depth and the side length of the pressure-bearing surface in the model, the theoretical solution of the frost-heaving pressure $P_{f}$ considering the depth of partial ponding was obtained as follows:

$$
P_{f}=\frac{\alpha h / 3}{3 / k_{r}+1 / k_{L}},
$$

where $\alpha$ is the volume expansion rate of water freezing into ice, $\alpha=9 \%$ here, $h$ is the maximum distance between the vertical lining and the constraining surface of the surrounding rock, $k_{r}$ and $k_{L}$ are the resistance coefficients of the lining and the surrounding rock.

The effects of the partial ponding depth, the restriction of surrounding rock on the volume expansion of water during its phase transforms into ice under low temperature, and the freezing time was considered. The theoretical solution of the space-time effect of frost-heaving pressure was obtained by substituting equation (2) into (1). The specific expression is as follows:

$$
\sigma_{f}=\frac{\alpha h k_{L}}{(3+9 / \gamma)\left(1+e^{-n\left(t-P_{t}\right)}\right)} .
$$

The compressive stiffness ratio of the lining and the surrounding rock was defined as follows:

$$
\gamma=\frac{k_{r}}{k_{L}} \text {. }
$$




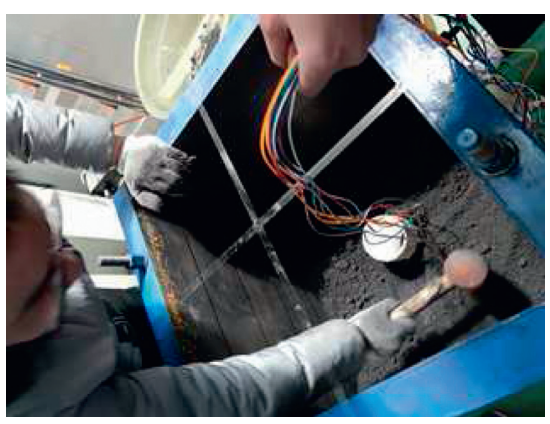

(a)

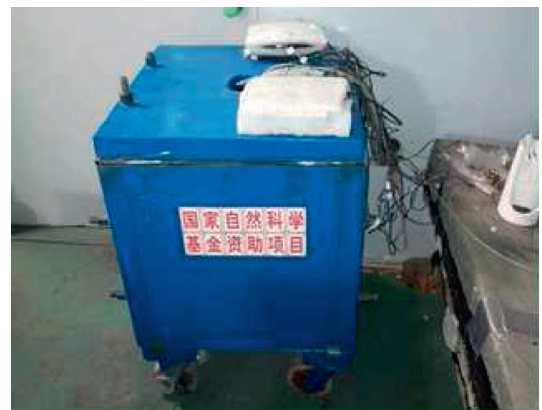

(d)

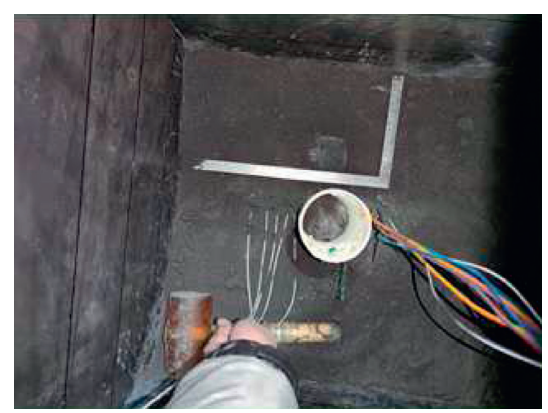

(b)

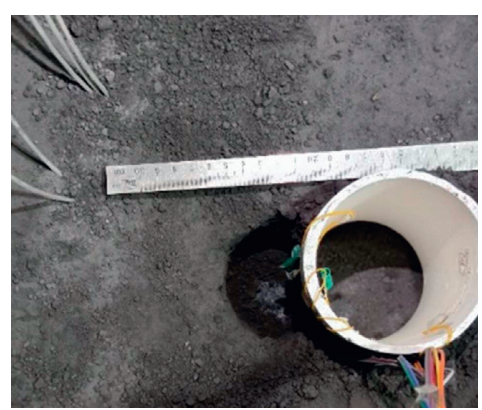

(c)

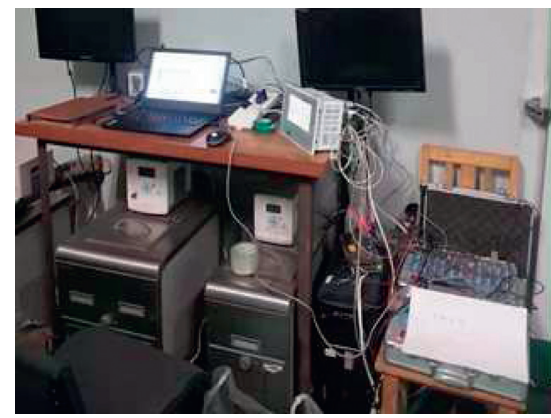

(e)

FIGURE 4: Test process: (a) lining model positioning, (b) sensor arrangement, (c) partial ponding, (d) model completed, and (e) data connection.

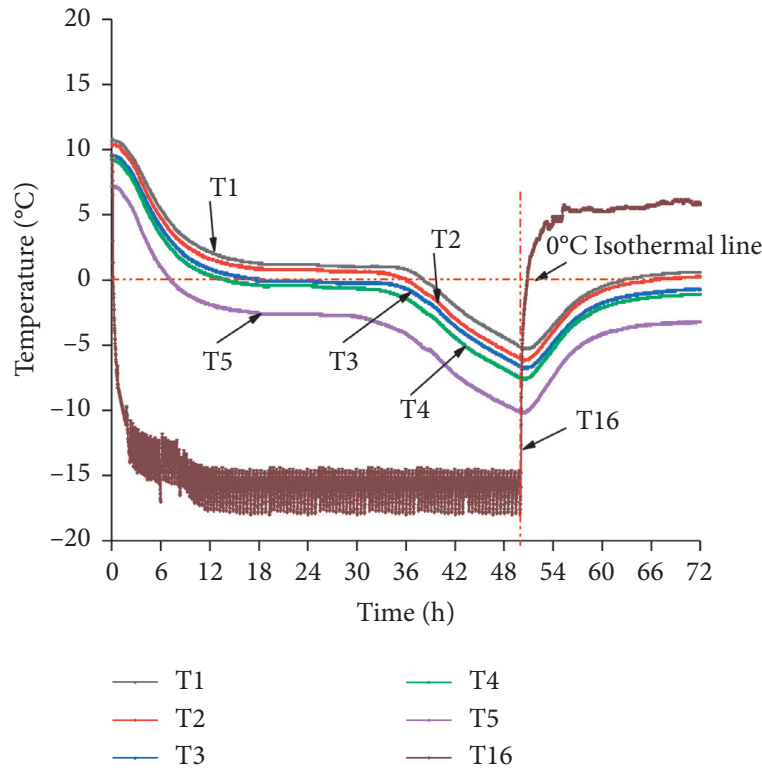

(a)

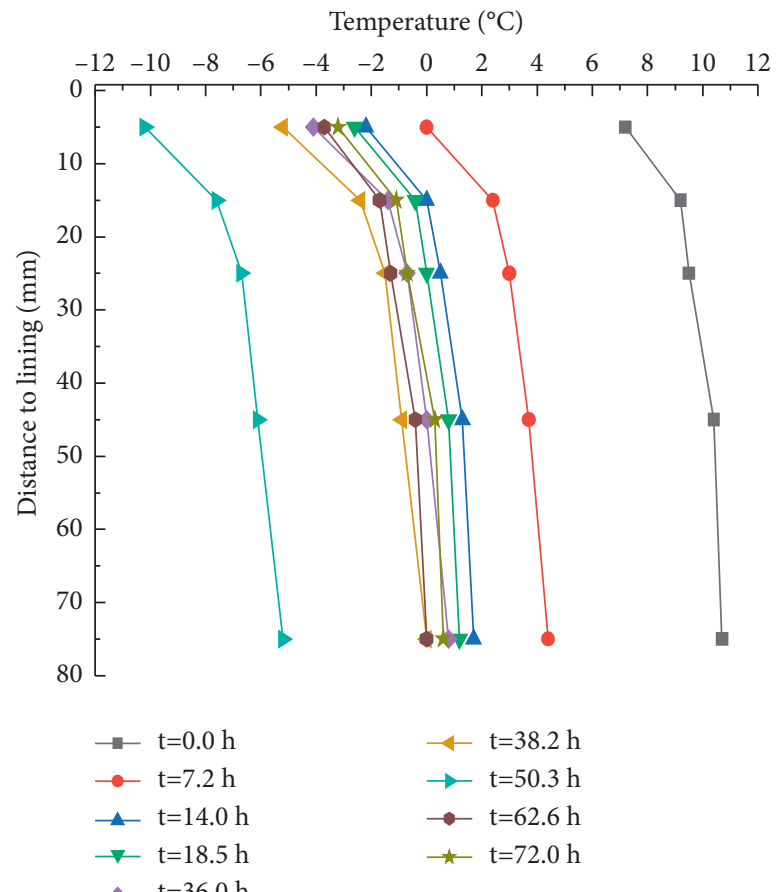

(b)

FIGURE 5: $100 \mathrm{~mm}$ section temperature distribution: (a) temperature curve with time and (b) temperature field along the radial direction.

5.2. Parameter Determination. Based on the calculation results in the literature, the resistance coefficient of the lining was set to $183.6 \mathrm{kPa} / \mathrm{mm}$, and the resistance coefficients of grades III, IV, and V surrounding rocks were set as the average values of the parameters of each grade, which were $850 \mathrm{kPa} / \mathrm{mm}, 350 \mathrm{kPa} / \mathrm{mm}$, and $150 \mathrm{kPa} / \mathrm{mm}$, respectively.

To intuitively study the effect of $n(0.3-0.9)$, we selected the maximum frost-heaving pressure $(155.2 \mathrm{kPa})$ at 


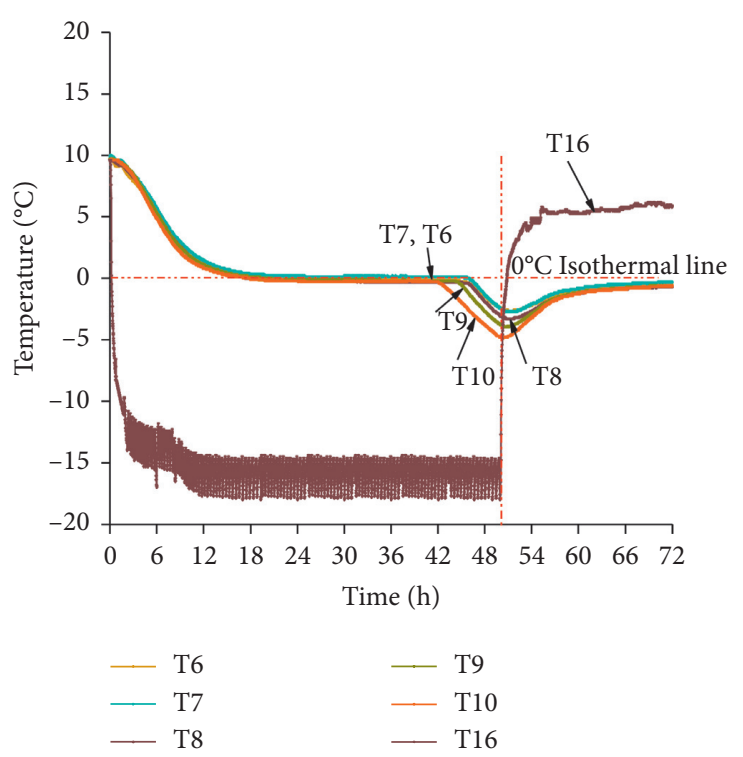

(a)

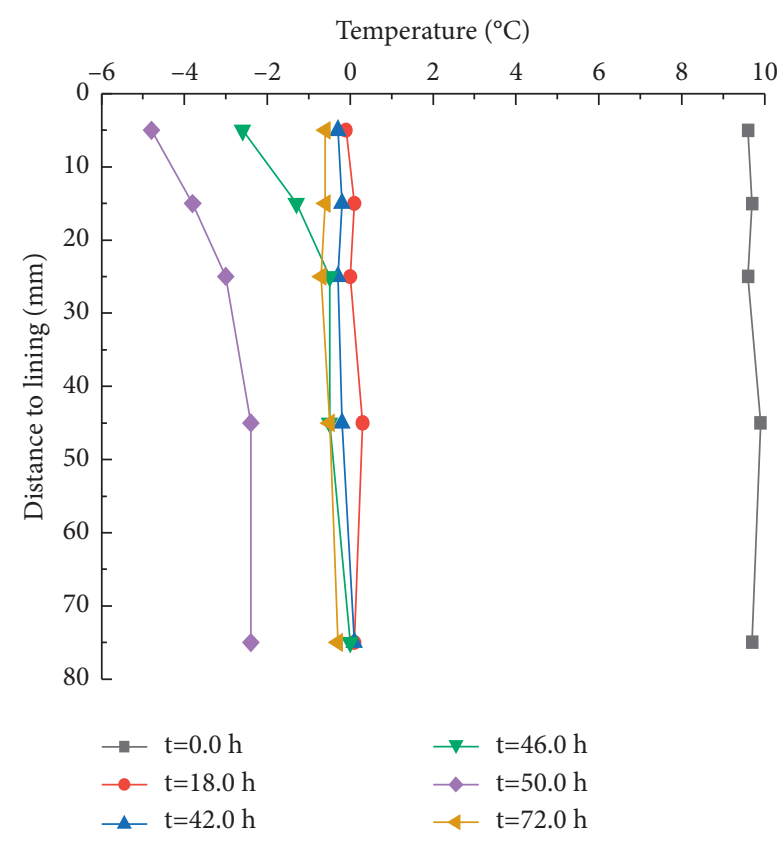

(b)

FIGURE 6: $300 \mathrm{~mm}$ section temperature distribution: (a) temperature curve with time and (b) temperature field along the radial direction.

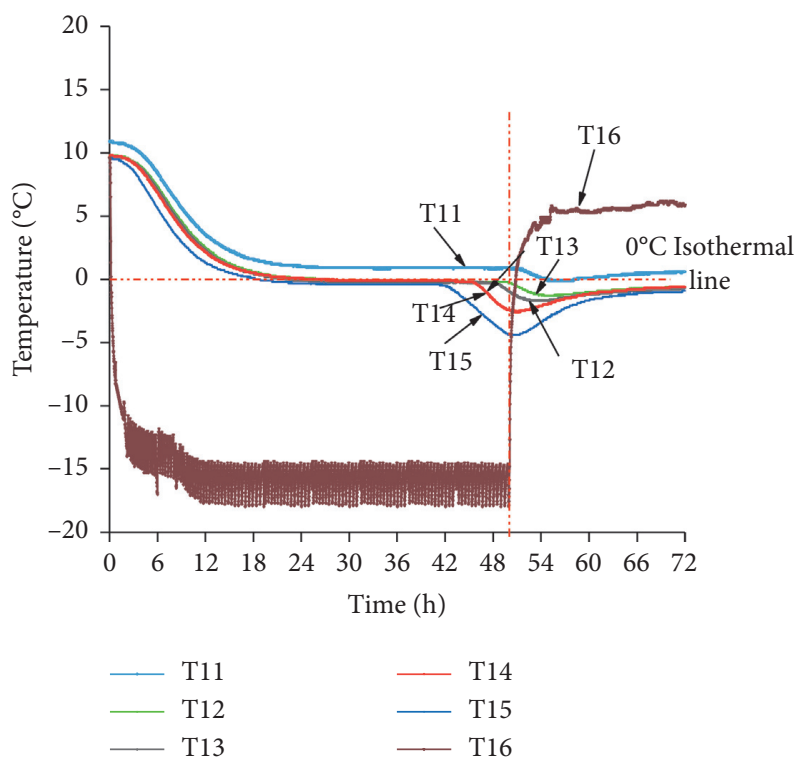

(a)

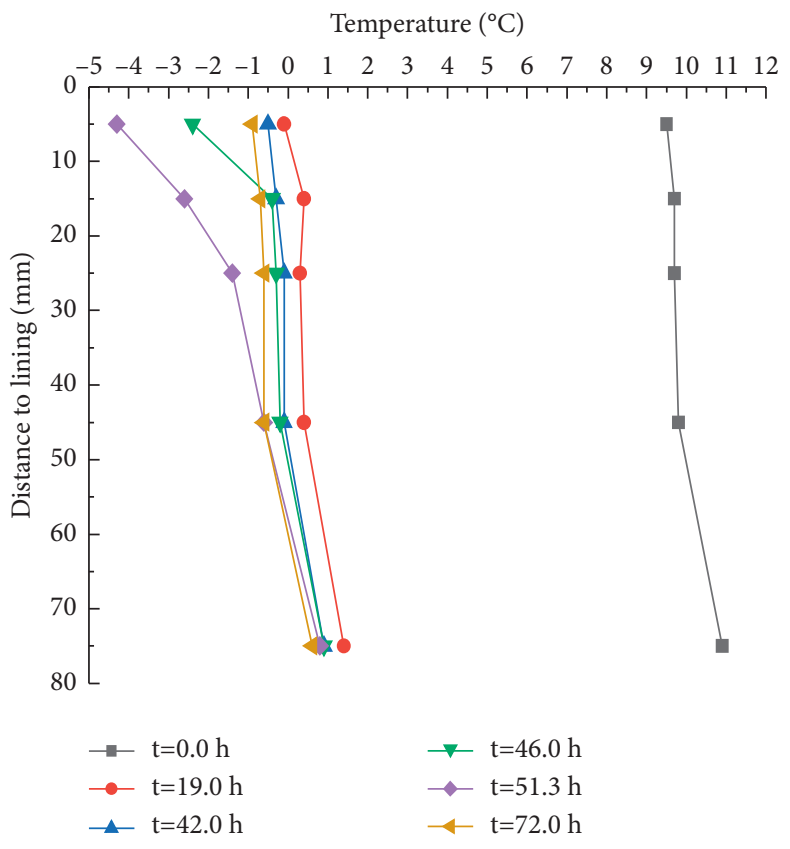

(b)

FiguRE 7: $500 \mathrm{~mm}$ section temperature distribution: (a) temperature curve with time and (b) temperature field along the radial direction.

measuring point 11-III-40 as the research variable, and the $t$ $n$ curve was plotted as shown in Figure 9. It is safe to conclude that the frost-heaving pressure growth coefficient $n$ determined the steepness of the frost-heaving pressure growth curve but not the frost-heaving pressure or the freezing time. According to the statistical data of the fitting curve in Table 4, the range of the values is 0.41 to 0.73 , and the average is 0.56 . To improve the simplification and 


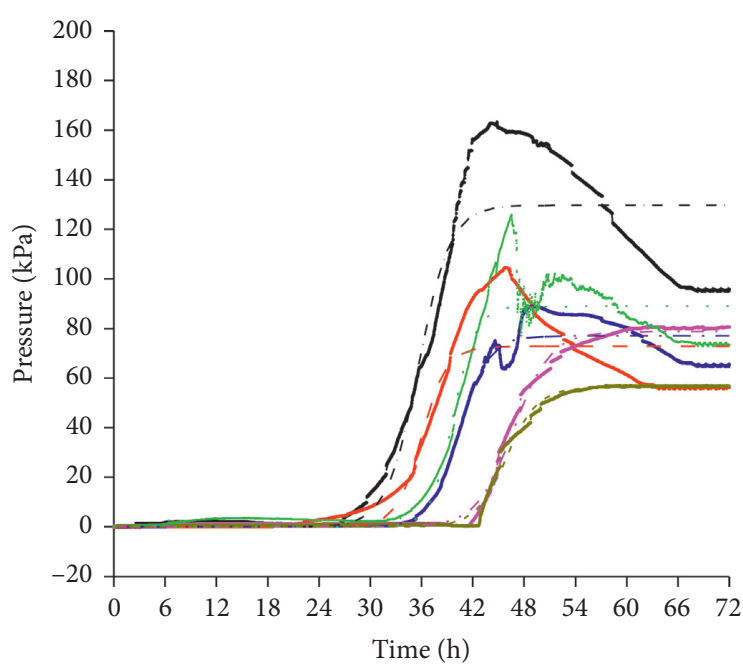

$$
\begin{aligned}
& \text {. -. - 1-III-40 } \\
& \text {-. 2-IV-40 } \\
& \text {-.. 3-III-30 } \\
& \text {-.. } 4 \text {-IV-30 } \\
& \text {-. - 5-III-20 } \\
& \text {-.. 6-IV-20 }
\end{aligned}
$$

(a)

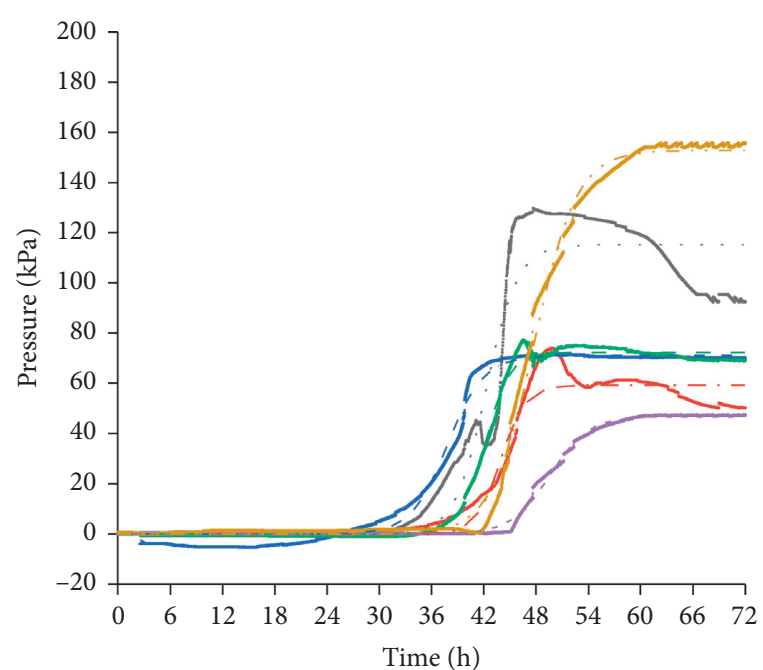

\begin{tabular}{|c|c|c|c|c|c|}
\hline \multirow{3}{*}{ Terms } & \multicolumn{5}{|c|}{ Parameters } \\
\hline & \multicolumn{2}{|c|}{$\begin{array}{c}\text { Maximum of frost-heaving } \\
\text { pressure } P_{\mathrm{f}} / \mathrm{kPa}\end{array}$} & \multirow[t]{2}{*}{ Freezing time $P_{t} / \mathrm{h}$} & \multirow[t]{2}{*}{ Growth factor $/ n$} & \multirow[t]{2}{*}{ Correlation coefficient $/ R_{2}$} \\
\hline & Test value & Fitted value & & & \\
\hline 1 -III-40 & 162.3 & 130.0 & 35.6 & 0.53 & 0.93 \\
\hline $2-\mathrm{IV}-40$ & 103.8 & 72.8 & 36.0 & 0.66 & 0.90 \\
\hline 3-III-30 & 110.4 & 88.9 & 39.7 & 0.75 & 0.96 \\
\hline $4-I V-30$ & 88.7 & 77.0 & 40.4 & 0.58 & 0.98 \\
\hline 5 -III-20 & 80.4 & 78.7 & 46.7 & 0.46 & 0.99 \\
\hline $6-I V-20$ & 56.7 & 56.1 & 45.9 & 0.55 & 0.99 \\
\hline 7-III-20 & 70.6 & 71.1 & 37.8 & 0.48 & 0.99 \\
\hline $8-\mathrm{V}-40$ & 75.0 & 72.4 & 42.2 & 0.71 & 0.99 \\
\hline 9-III-30 & 129.0 & 115.2 & 42.3 & 0.55 & 0.96 \\
\hline $10-\mathrm{V}-30$ & 73.6 & 59.3 & 44.0 & 0.67 & 0.97 \\
\hline $11-$ III-40 & 155.2 & 152.8 & 47.8 & 0.41 & 0.99 \\
\hline $12-\mathrm{V}-20$ & 47.3 & 46.9 & 49.6 & 0.45 & 0.99 \\
\hline
\end{tabular}

$$
\begin{array}{ll}
\cdot-\cdot- & 7-\mathrm{III}-20 \\
-\cdot- & 8-\mathrm{V}-40 \\
-.- & 9-\mathrm{III}-30 \\
-.- & 10-\mathrm{V}-30 \\
- & 11-\mathrm{III}-40 \\
-.- & 12-\mathrm{V}-20
\end{array}
$$

-. - fitting of 7-III-20

-. - fitting of 8-V-40

- - f fitting of 9-III-30

-. - fitting of $10-\mathrm{V}-30$

-. - fitting of 11-III-40

- - fitting of $12-\mathrm{V}-20$

(b)

FIGURE 8: Frost-heaving pressure and fitting curve: (a) 1-6\# frost-heaving pressure and fitting curve and (b) 7-12\# frost-heaving pressure and fitting curve.

TABLE 5: Frost-heaving pressure and fitting parameters.

Notes: taking "1-III-40" for example, "1" represents the test terms. III represents grade III surrounding rock classification. 20 represents the thickness of partial ponding. The following is the same as well.

applicability of the frost-heaving pressure equation, we set $n$ to 0.5 to finally give the simplified semiempirical solution of the frost-heaving pressure considering the space-time effect.

$$
\sigma_{f}=\frac{\alpha h k_{L}}{(3+9 / \gamma)\left(1+e^{-\left(t-P_{t}\right) / 2}\right)} .
$$

According to equation (5), the frost-heaving pressure is in direct proportion to the depth of partial ponding, and the equation can reflect the temporal and spatial evolution of frost-heaving pressure. Since the variation range of frostheaving pressure is definite and predictable, the equation has a certain application value for the estimation of frostheaving pressure in cold region tunnels.

To verify the applicability of the proposed semiempirical solution for the frost-heaving pressure considering the space-time effect, we substituted the experimental results and theoretical results into equation (5) and inversely analyzed the frost-heaving pressure variation pattern with time at different depths of partial ponding. The curves of the 


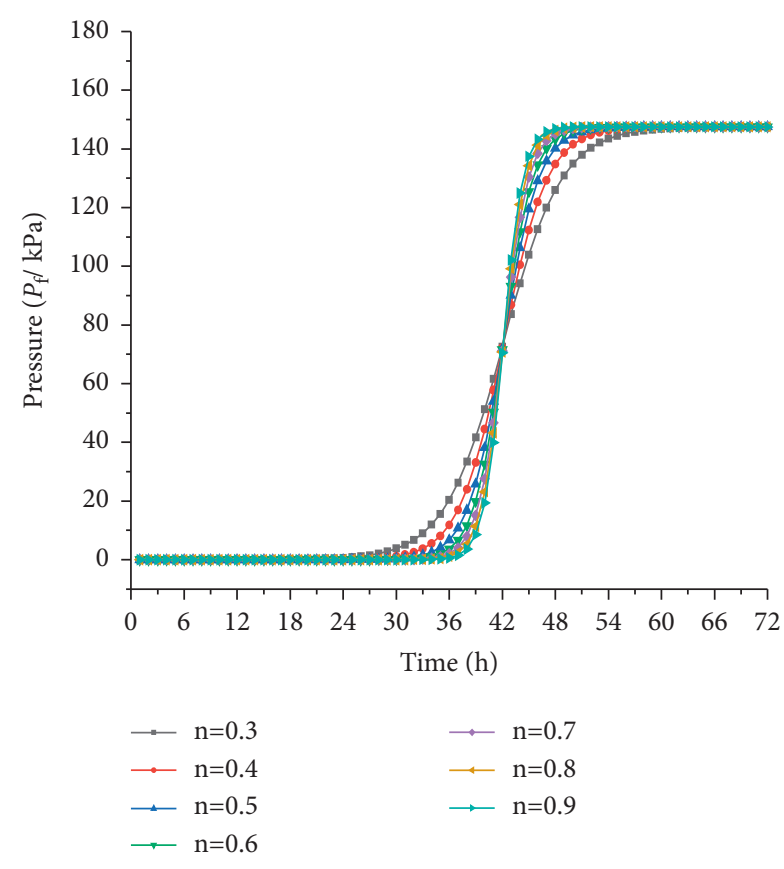

Figure 9: $t$ - $n$ curve.

experimental results and the semi-empirical solutions are plotted as shown in Figure 10. The frost-heaving pressure curves based on the regression data and the theoretical results are in good agreement, indicating that the calculation model in this paper can reflect the evolution pattern of frostheaving pressure over time.

\subsection{Numerical Calculation of Frost-Heaving Pressure}

5.3.1. Numerical Model. To study the frost heave characteristics of the partial ponding, which was affected by factors such as depths of water and the levels of the surrounding rock being confined, numerical simulations of multiengineering conditions can be considered. Therefore, it was further verified with the frost heave model test results and theoretical analysis after enlarging the scaled model in a similar proportion to the design size of the Guigala highway tunnel in Tibet of China. The three-dimensional numerical calculation model was established as shown in Figure 11. The longitudinal length of the model is $10 \mathrm{~m}$, the width is $60 \mathrm{~m}$, and the height is $60 \mathrm{~m}$. Both the surrounding rock and the lining are simulated with 8-node 3D solid element Solid45. The effects of different volumes of partial ponding were simulated by changing the height $h$ of the triangular void.

5.3.2. Parameter Analysis. The frost-heaving pressure of partial ponding is calculated by the method of thermal stress. The volume expansion coefficient caused by freezing is regarded as a negative thermal expansion coefficient, which is assigned to the water body to achieve the simulation of frost-heaving pressure. Assuming that ice expands is isotropy, and its linear expansion coefficient can be obtained as 0.029 [33]. The specific mechanical parameters of the materials used in the calculation are listed in Table 6.

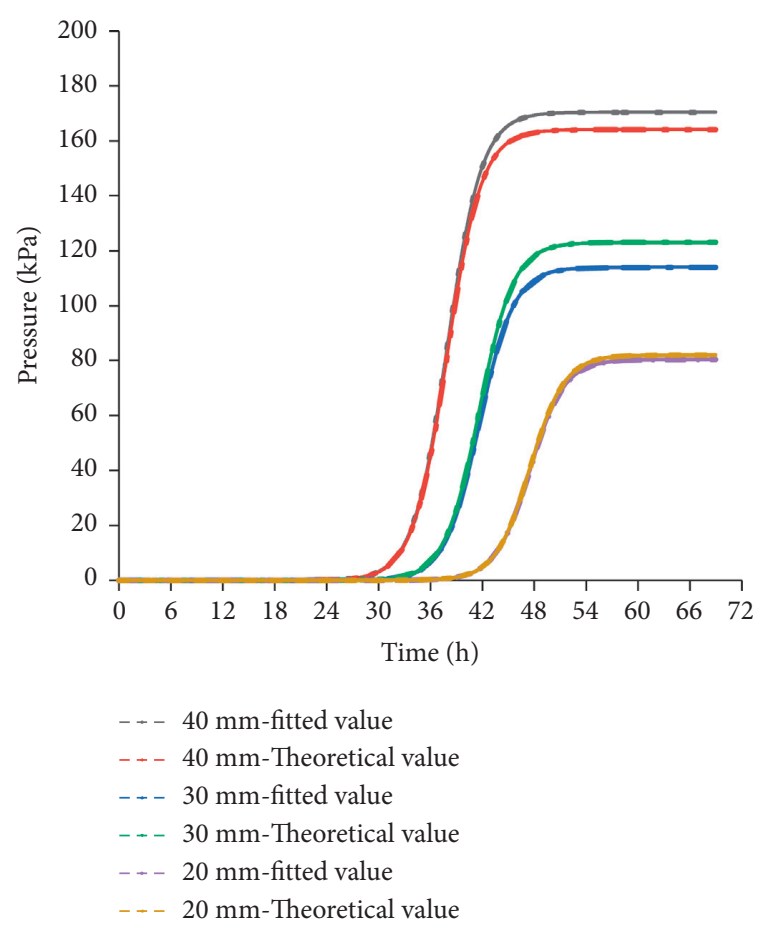

Figure 10: Spatio-temporal evolution curve of frost-heaving pressure.

The elastic resistance coefficient $K$ has the following relationship with the elastic modulus $E$ and Poisson's ratio $\mu$ [34].

$$
K=\frac{E}{(1+\mu) r_{0}},
$$

where $r_{0}$ is the radius of the designed tunnel, $m$.

5.3.3. Computational Numerical Verification. The simulated values were scaled to the model test dimensions according to the similarity relationship. Then the experimental test values, fitting values, and theoretical calculation values were compared with the simulation ones. Figure 12 shows that the numerical simulation values are basically consistent with the experimental results, but both results are larger than the theoretical calculation ones. Taking the V-level surrounding rock condition as an example, the thickness of the partial ponding is $20 \mathrm{~mm}$, the test result of frost-heaving pressure is $47.3 \mathrm{kPa}$, the numerical simulation value is $43.3 \mathrm{kPa}$, and the numerical difference between the two values is $9.2 \%$ of the simulated value. The theoretical value is $27.8 \mathrm{kPa}$, which is $35.8 \%$ smaller than the simulated value. The aforementioned results show that the numerical solution was reliable, and the theoretical solution had a law of linear distribution, which can provide a certain reference significance. Since the theoretical results were calculated based on the three-dimensional space model of a regular tetrahedron, and the results depend on the size of the model, which may be the reason that the calculation results are smaller than the simulated ones. 


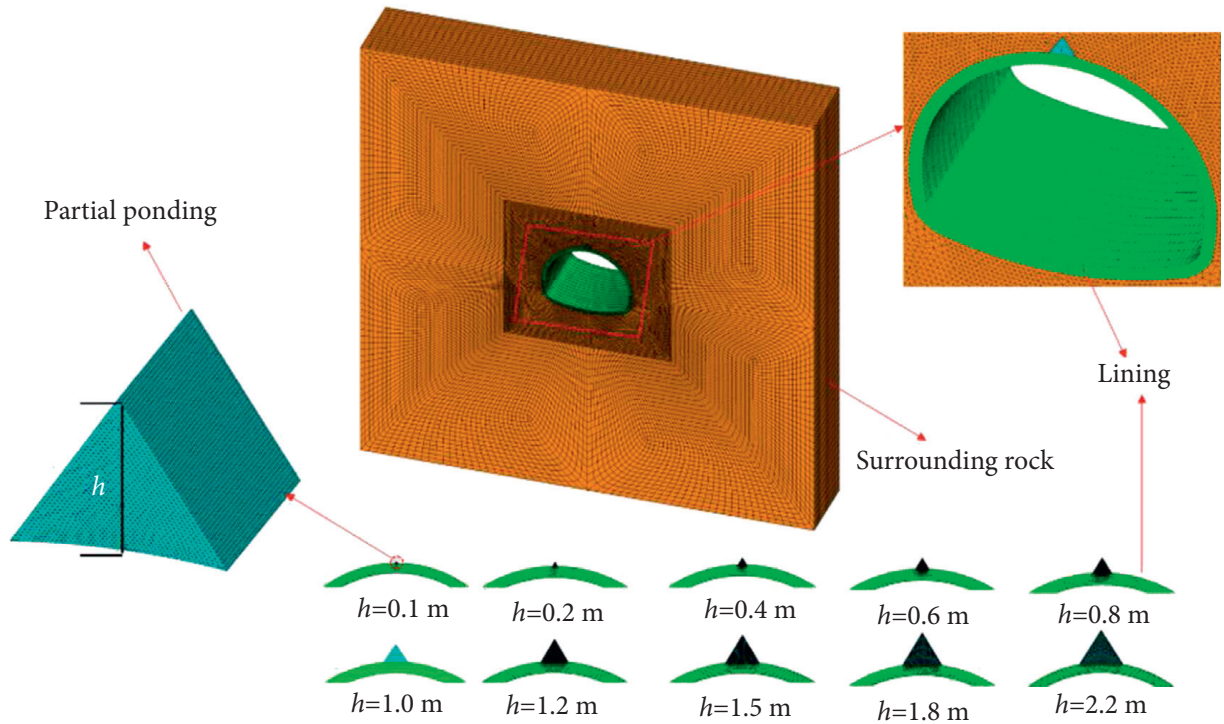

Figure 11: Numerical computation model.

TABLE 6: Numerical simulation parameters.

\begin{tabular}{|c|c|c|c|c|c|}
\hline Materials & $\begin{array}{l}\text { Surrounding rock level } \\
\text { III }\end{array}$ & $\begin{array}{l}\text { Surrounding rock level } \\
\text { IV }\end{array}$ & $\begin{array}{c}\text { Surrounding rock level } \\
\mathrm{V}\end{array}$ & $\begin{array}{c}\text { Lining } \\
\text { concrete }\end{array}$ & Ice \\
\hline Weight capacity/(kN/m³) & $26.5-24.5$ & $24.5-22.5$ & $<22.5$ & 23 & 9.0 \\
\hline $\begin{array}{l}\text { Elastic modulus/Deformation modulus } \\
(\mathrm{GPa})\end{array}$ & $16.0-6.0$ & $6.0-1.3$ & $<1.3$ & 28.5 & 11.0 \\
\hline Poisson ratio $\mu$ & $0.25-0.30$ & $0.30-0.35$ & $>0.35$ & 0.2 & 0.3 \\
\hline
\end{tabular}

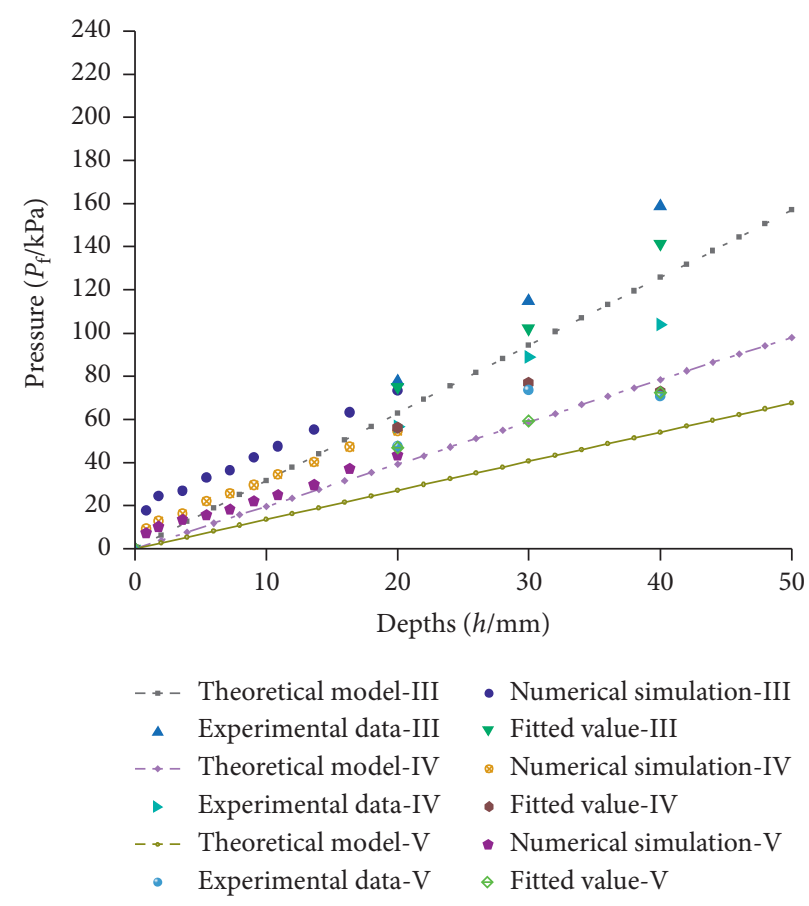

FIGURE 12: Law of frost-heaving pressure with different depths.

5.3.4. Influence of Surrounding Rock Elastic Resistance Coefficient. Figure 13 shows the evolution law of frostheaving pressure and different thickness of partial ponding with elastic resistance coefficient of surrounding rock. It can be seen that as the thickness of partial ponding and elastic resistance coefficient increases, the frost-heaving 


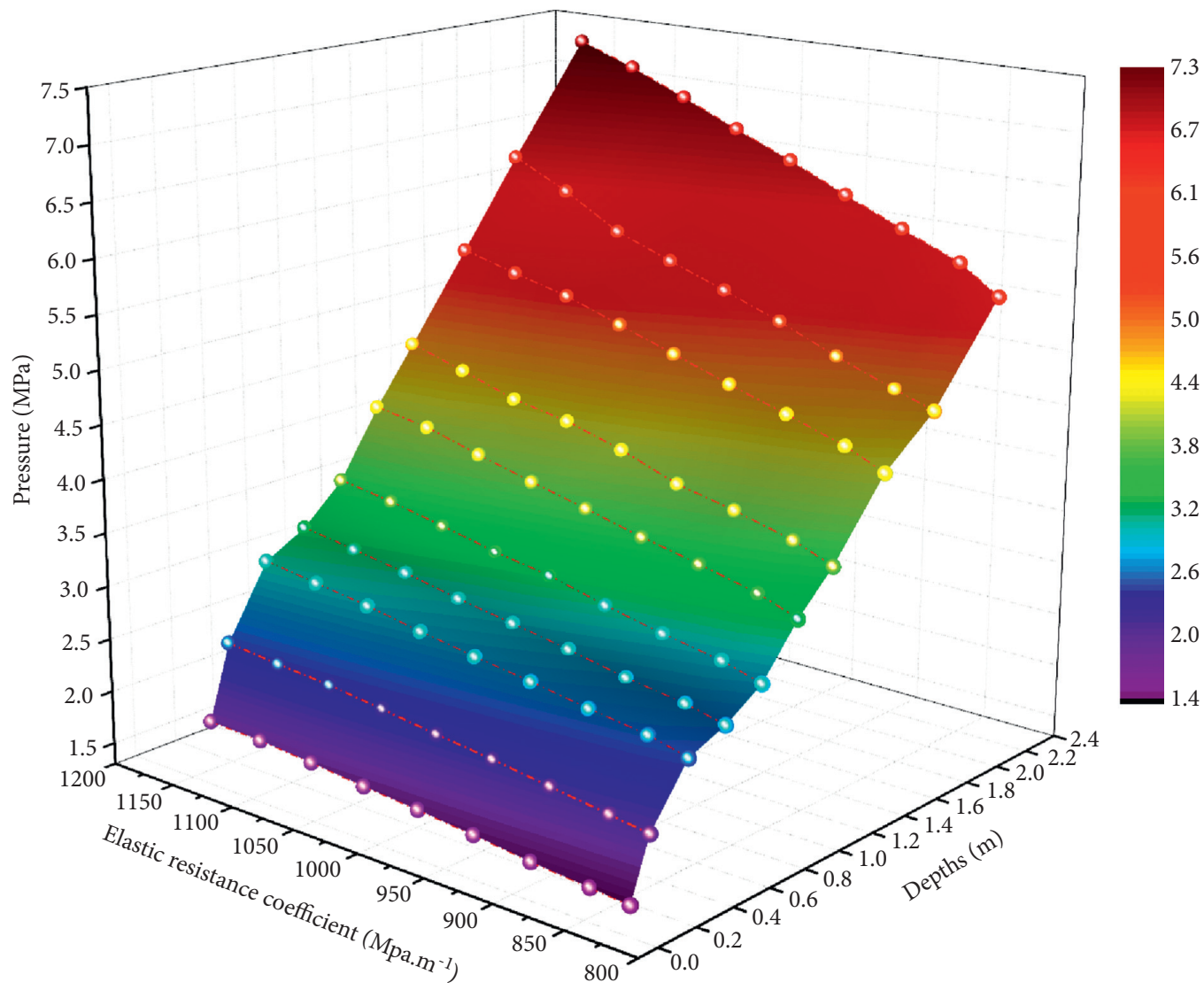

(a)

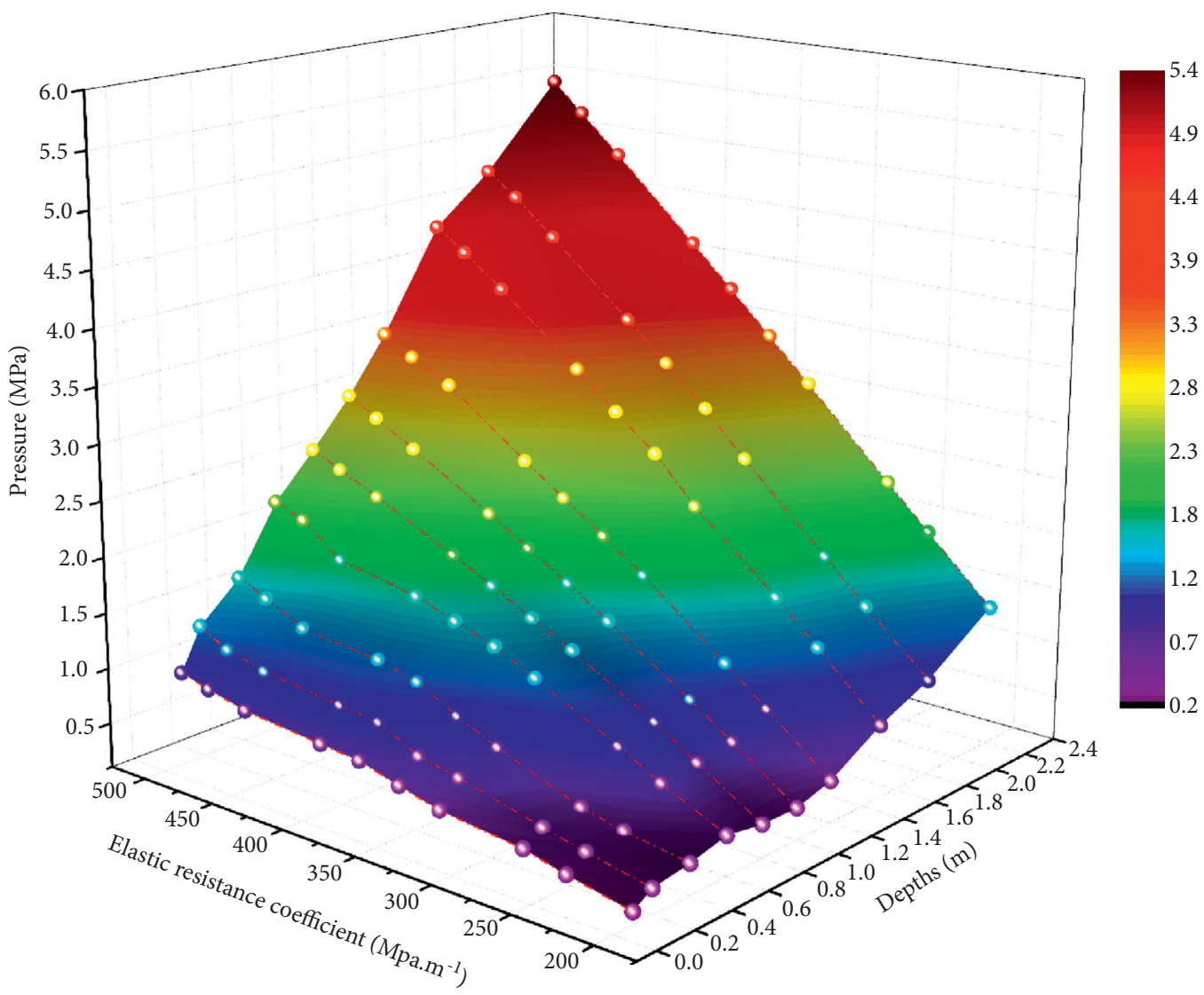

(b)

Figure 13: Continued. 


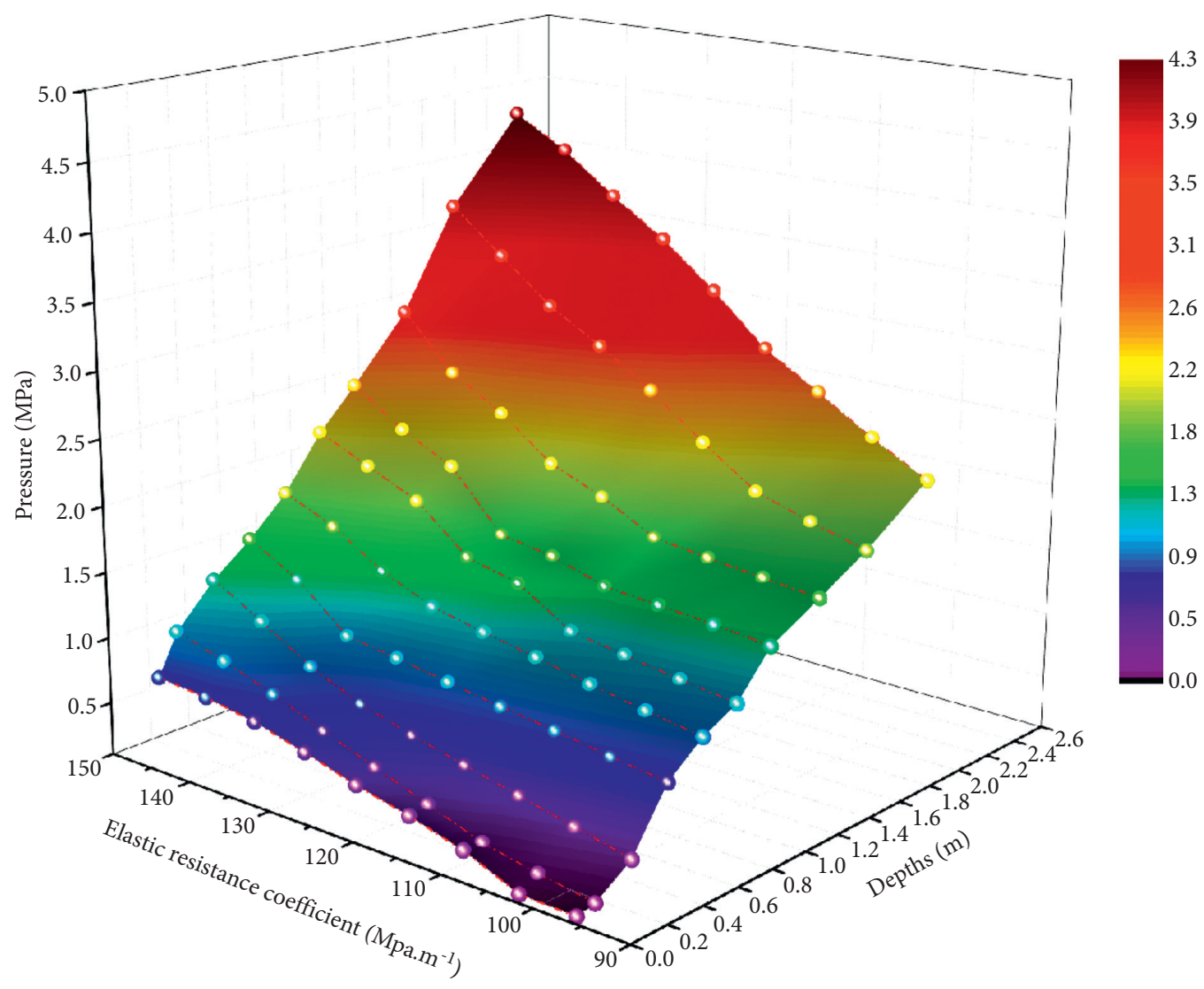

(c)

FIGURE 13: Evolution law of frost-heaving pressure with elastic resistance coefficient: (a) surrounding rock level III, (b) surrounding rock level IV, and (c) surrounding rock level V.

pressure increases. The frost-heaving pressure between different ponding water thicknesses has a parallel distribution characteristic, which indicating that the influence of water thickness on the distribution of frost-heaving pressure is linear. The results can be used as a reference for guiding the value of frost-heaving pressure at the engineering site.

\section{Conclusion}

TThe ge-mechanical model test considered the evolution patterns of frost heaving pressure with partial ponding in cold region tunnels. According to the experimental data, the theoretical model of the temporal and spatial evolution of the frost-heaving pressure was studied; the main conclusions are as follows:

(1) The temperature field was the determining condition for the frost heave at tunnel portal. With the increase of freezing time, the temperature field of surrounding rock decreased first and stabilized before decreasing again. The time when the temperature field began rapid dropping was closely related to the freezing time that produced the frost-heaving pressure. The temperature was easy to measure in cold region tunnels, which could serve as important information to determine the evolution of frostheaving pressure.

(2) Nonlinear fitting was performed on the measured frost-heaving pressure, and the theoretical frostheaving pressure model was built about the spatiotemporal characteristics considering the thickness of partial ponding and the elastic resistance coefficient of the surrounding rock, which could reflect the temporal and spatial evolution of frost-heaving pressure.

(3) The frost-heaving pressure is an integrative result of the thickness of partial ponding and elastic resistance coefficient of the surrounding rock, and the results augment with the increase of the both values. The evolution law of the frost-heaving pressure can be predicted, and its magnitude is calculated using the methods in this paper, which has a certain application for the frost-heaving pressure of partial ponding behind tunnels in cold regions.

\section{Data Availability}

The data support in the results of this study are reported in the figures and tables. 


\section{Conflicts of Interest}

The authors declare that they have no conflicts of interest.

\section{Acknowledgments}

This work was supported by the National Natural Science Foundation of China (grant nos. 51808359, 52078311, and 51991395), the Fundamental Research Funds for the Central Universities, CHD (grant no. 300102211518), the Young Talent Top Project of Hebei Province (grant no. BJ2020055), the Hebei Provincial Natural Science Foundation of China (grant no. E2019210356), the China Postdoctoral Science Foundation (grant no. 2019M663553), and the Young Elite Scientists Sponsorship Program by CAST (grant no. 2018QNRC001), the Shenzhen Science and Technology Program (grant no. KQTD20180412181337494), and the State Key Laboratory for GeoMechanics and Deep Underground Engineering, China University of Mining and Technology/China University of Mining and Technology, Beijing (grant no. SKLGDUEK1916).

\section{References}

[1] X. Tan, W. Chen, D. Yang et al., "Study on the influence of airflow on the temperature of the surrounding rock in a cold region tunnel and its application to insulation layer design," Applied Thermal Engineering, vol. 67, no. 1-2, pp. 320-334, 2014.

[2] Y. Lai, Z. Wu, and S. Zhang, "In-situ observed study for effect of heat preservation in cold regions tunnels," Journal of the China Railway Society, vol. 25, no. 1, pp. 81-86, 2003.

[3] G. Bai, W. Qiu, and J. Zhang, "Study on classification standard of frost heave force for tunnels in frozen zone," Tunnel Construction, pp. 104-108, 2007.

[4] D. Zhang, M. Wang, and Z. Tan, "Effect of frost heaving on tunnel surpporting systems of Fenghuoshan Railway Tunnel," Chinese Journal of Geotechnical Engineering, vol. 5, pp. 571573, 2003.

[5] Y. Wang, H. N. Yang, J. Q. Han, and C. Zhu, "Effect of rock bridge length on fracture and damage modelling in granite containing hole and fissures under cyclic uniaxial increasingamplitude decreasing-frequency (CUIADF) loads," International Journal of Fatigue, vol. 158, Article ID 106741, 2022.

[6] Y. Wang, B. Zhang, B. Li, and C. Li, "A strain-based fatigue damage model for naturally fractured marble subjected to freeze-thaw and uniaxial cyclic loads," International Journal of Damage Mechanics, vol. 30, no. 10, pp. 1594-1616, 2021.

[7] Y. Zeng, K. Liu, X. Zhou, and L. Fan, “Tunnel temperature fields analysis under the couple effect of convection-conduction in cold regions," Applied Thermal Engineering, vol. 120, pp. 378-392, 2017.

[8] X. Zhao, X. Yang, H. Zhang, H. Lai, and X. Wang, "An analytical solution for frost heave force by the multifactor of coupled heat and moisture transfer in cold-region tunnels," Cold Regions Science and Technology, vol. 175, Article ID 103077, 2020.

[9] H. Liu, X. Yuan, and T. Xie, "A damage model for frost heaving pressure in circular rock tunnel under freezingthawing cycles," Tunnelling and Underground Space Technology, vol. 83, pp. 401-408, 2019.

[10] C. Xia, Z. Lyu, and Y. Wang, "Advance and review on frost heaving force calculation methods in cold region tunnels,"
China Journal of Highway and Transport, vol. 33, pp. 35-43, 2020.

[11] Z. Zhang and L. Wang, "Discussion on the design of tunnel in high elevation and bitter cold region," Modern Tunneling Technology, vol. 41, pp. 1-6, 2004.

[12] Y. Zhang, Y. Xie, and Y. Li, "A frost heave model based on space-time distribution of temperature field in cold region tunnels," Rock and Soil Mechanics, vol. 39, pp. 1625-1632, 2018 b.

[13] Y. Lai, Z. Wu, and Y. Zhu, "Analytical viscoelastic solution for frost force of cold regional tunnels," Journal of the China Railway Society, vol. 21, pp. 70-74, 1999.

[14] Z. Lyu, C. Xia, and W. Liu, "Analytical solution of frost heaving force and stress distribution in cold region tunnels under non-axisymmetric stress and transversely isotropic frost heave of surrounding rock," Cold Regions Science and Technology, vol. 178, Article ID 103117, 2020.

[15] G. Y. Gao, Q. S. Chen, Q. S. Zhang, and G. Q. Chen, “Analytical elasto-plastic solution for stress and plastic zone of surrounding rock in cold region tunnels," Cold Regions Science and Technology, vol. 72, pp. 50-57, 2012.

[16] Q. Feng, B.-S. Jiang, Q. Zhang, and L.-p. Wang, "Analytical elasto-plastic solution for stress and deformation of surrounding rock in cold region tunnels," Cold Regions Science and Technology, vol. 108, pp. 59-68, 2014.

[17] Q. Feng, W.-w. Liu, and B.-S. Jiang, "Analytical solution for the stress and deformation of rock surrounding a cold-regional tunnel under unequal compression," Cold Regions Science and Technology, vol. 139, pp. 1-10, 2017.

[18] Z. Lv, C. Xia, Y. Wang, and J. Luo, "Analytical elasto-plastic solution of frost heaving force in cold region tunnels considering transversely isotropic frost heave of surrounding rock," Cold Regions Science and Technology, vol. 163, pp. 87-97, 2019.

[19] D. Wang, J. Yuan, Y. Zhu, Y. Luan, H. Cui, and G. Cui, "Safety evaluation and action mechanism of frost heave with local water storage in shallow tunnel," Journal of Traffic and Transportation Engineering, vol. 20, pp. 40-50, 2020.

[20] J. Wang and Y. Hu, "A discussion on frost-heaving force on tunnel lining," Journal of Glaciology and Geocryology, vol. 26, pp. 112-119, 2004.

[21] L. Fan, Y. Zeng, and C. He, "Magnitude and distribution of frost heave force for cold region strong rock tunnels," China Railway Science, vol. 28, pp. 44-49, 2007.

[22] G. Deng, J. Wang, and J. Zheng, "Model of constraint on deformation due to frost heave for tunnels in cold region," China Journal of Highway and Transport, vol. 23, pp. 80-85+110, 2010.

[23] X. Zhang, Z. Zhou, J. Li, Y. Zhou, and F. Han, “A physical model experiment for investigating into temperature redistribution in surrounding rock of permafrost tunnel," Cold Regions Science and Technology, vol. 151, pp. 47-52, 2018.

[24] Y. Yu, X. Ling, L. Tang, X. Han, L. Geng, and S. Wei, "Preliminary identification of the failure mode of shallow tunnels in soil subjected to frost heave: model test and numerical simulation," Transportation Geotechnics, vol. 29, Article ID 100555, 2021.

[25] Y. Zhang, J. Lai, and J. Qiu, "Test and analysis on frost heaven effects of cold region tunnel," Journal of Traffic and Transportation Engineering, vol. 18, pp. 64-73, 2018.

[26] J. Chen and Y. Za'n, "Field test and analysis of antifreezing thermal-protective layer effect of the highway tunnel in cold area," Journal of Highway and Transport, vol. 14, no. 4, pp. 75-79, 2001. 
[27] J. Yan, C. He, and Q. Yan, "In-situ test and calculation of frost heaving force of ice moraine stratum in Que'er moutainu tunnel," Rock and Soil Mechanics, vol. 40, no. 9, Article ID 3593, 2019.

[28] W. Qiu and B. Sun, "Model test study of frost heaving pressures in tunnels excavated in fractured rock mass in cold regions," Journal of Glaciology and Geocryology, vol. 32, pp. 557-561, 2010.

[29] M. Qu, Q. Xie, and Y. Hu, "A model test study on frost heaving pressures on tunnel lining in cold region," Chinese Journal of Rock Mechanics and Engineering, vol. 34, pp. 1894-1900, 2015.

[30] X. Zheng, Motel Test Research on Mechanical Characteristics of Subway Station Construction in Finite Space Adjoining Structure, Shijiazhuang Tiedao University, Shijiazhuang, China, 2017.

[31] Y. Fang, J. Guo, and H. Kang, "Influence of voids behind lining on the mechanical behavior of lining structure of highway tunnel in watery strata," Chinese Journal of Rock Mechanics and Engineering, vol. 35, no. 8, pp. 1648-1658, 2016.

[32] S. Huang, Q. Liu, and A. Cheng, "Preliminary experimental study of frost heaving pressure in crack and frost heaving propagation in rock mass under low temperature," Rock and Soil Mechanics, vol. 39, no. 1, pp. 78-84, 2018.

[33] C. He and H. Xie, Application of Multi-Field Coupling Analysis in Tunnel Engineering, Southwest Jiaotong University Press, Chengdu, China, 2015.

[34] Z. Lu, Engineering Geology, China Construction Industrial Publishing House, Beijing, China, 2001. 